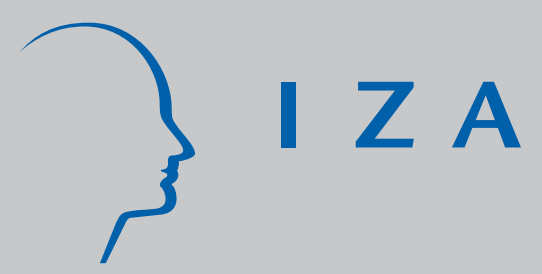

IZA DP No. 478

Uneven Technical Progress and Unemployment

Hans Gersbach

Achim Schniewind

April 2002 


\title{
Uneven Technical Progress and Unemployment
}

\author{
Hans Gersbach \\ Alfred Weber Institute, University of Heidelberg \\ and IZA, Bonn \\ Achim Schniewind \\ Alfred Weber Institute, University of Heidelberg
}

Discussion Paper No. 478

April 2002

\author{
IZA \\ P.O. Box 7240 \\ D-53072 Bonn \\ Germany \\ Tel.: +49-228-3894-0 \\ Fax: +49-228-3894-210 \\ Email: iza@iza.org
}

This Discussion Paper is issued within the framework of IZA's research area Welfare State and Labor Markets. Any opinions expressed here are those of the author(s) and not those of the institute. Research disseminated by IZA may include views on policy, but the institute itself takes no institutional policy positions.

The Institute for the Study of Labor (IZA) in Bonn is a local and virtual international research center and a place of communication between science, politics and business. IZA is an independent, nonprofit limited liability company (Gesellschaft mit beschränkter Haftung) supported by the Deutsche Post AG. The center is associated with the University of Bonn and offers a stimulating research environment through its research networks, research support, and visitors and doctoral programs. IZA engages in (i) original and internationally competitive research in all fields of labor economics, (ii) development of policy concepts, and (iii) dissemination of research results and concepts to the interested public. The current research program deals with (1) mobility and flexibility of labor markets, (2) internationalization of labor markets and European integration, (3) welfare state and labor markets, (4) labor markets in transition, (5) the future of work, (6) project evaluation and (7) general labor economics.

IZA Discussion Papers often represent preliminary work and are circulated to encourage discussion. Citation of such a paper should account for its provisional character. A revised version may be available on the IZA website (www.iza.org) or directly from the author. 
IZA Discussion Paper No. 478

April 2002

\section{ABSTRACT}

\section{Uneven Technical Progress and Unemployment ${ }^{*}$}

In a two-sector model with real wage rigidity, we examine how technical progress in one sector affects unemployment in the whole economy. We show that aggregate unemployment decreases for uneven technical change in the case of Cobb-Douglas production functions. For every type of technical progress, however, there are also elasticities of substitution in production and utility functions leading to a rise in unemployment. Moreover, we identify polar cases when unemployment strongly decreases.

JEL Classification: D58, E24, J60, L13

Keywords: uneven technical progress, elasticities of substitution, unemployment

Hans Gersbach

Alfred-Weber-Institut

Universität Heidelberg

Grabengasse 14

69117 Heidelberg

Germany

Tel.: +49-6221-54 3173

Fax: +49-6221-54 3578

Email: hans@gersbach.de

\footnotetext{
"We would like to thank Volker Hahn, George Sheldon, Robert Solow and conference participants at the IZA workshop on economic integration 2000 and seminar participants in Heidelberg and IZA summer school 1999 for helpful comments and suggestions.
} 


\section{Introduction}

Productivity improvements are the most important factors leading to economic growth and an increase in material well-being. In contrast, sectoral productivity improvements are often associated with job losses and therefore lead to worker opposition.

The problem behind this apparent contradiction is that technological progress does not usually take place uniformly across all sectors in the economy. This may occur temporarily, but uneven technical progress may occur over very long time horizons as well. This has been indicated by the differential growth rates in total factor productivity between the manufacturing and the service industry in industrial countries for many decades. Sectoral productivity improvements typically occur also when state-owned industries are privatized. Examples can be observed in transition economies but also in developed countries (see the deregulation of telecommunication in West European countries and the US). An insightful exploration of uneven technological progress can be found in Baumol, Blackman and Wolf (1989). ${ }^{1}$

In this paper we examine the short-term relationship between technical progress in only one sector and unemployment. In a two-sector model with real wage rigidity, we examine the three standard types of uneven technological progress (Hicks neutral, Harrod neutral and Solow neutral). We allow for different degrees of complementarities between consumption goods and between production factors as expressed by different elasticities of substitution.

We show that if both sectors produce with Cobb-Douglas technologies and the same labor and capital shares, unemployment unambiguously decreases when technical progress (of any kind) occurs. We also show that aggregate unemployment may rise or fall given any type of technical progress. Whether unemployment rises or falls is determined by the joint levels of elasticities of substitution between consumption goods on the demand side and production factors (labor and capital) on the supply side.

Our paper may have applications for the impact of product market reforms concerning unemployment in Europe. Promoting competition in product markets is concerned with relaxing entry and exit barriers through regulation or deregulation. Extreme

\footnotetext{
${ }^{1}$ See also Dollar and Wolf (1993), van Ark and Pilat (1993), Baily and Gersbach (1995).
} 
cases are the privatization and deregulation of the telecommunication and postal service industries. As discussed in a series of papers based on productivity studies at the McKinsey Global Institute (Baily 1993, Baily and Gersbach 1995, Gersbach and Sheldon 1996, Börsch-Supan [1999], product market reforms in Europe have the potential to foster total factor productivity gains in a variety of industries. Furthermore, Anderson [2000] highlights that product market integration in Europe may lead to a more unequal distribution of wages and employment, despite aggregate gains in terms of higher real incomes and employment. Burda [1999] shows that shop closing laws tend to have a negative effect on employment and output. The effect on welfare is ambiguous when there are gains from synchronization of time. Gersbach [2000] provides a survey on whether product market reforms could help to reduce unemployment in Europe.

Moreover, the comprehensive econometric studies by Green and Mayes [1991], Hay and Liu [1997] and Nickell [1996] provide evidence that productivity levels or growth rates are, on average, negatively correlated with market power. Thus, increasing competition may cause productivity improvements by inducing organizational and design changes. ${ }^{2}$ Our paper focuses on short term effects of product market reforms, i.e. sectoral productivity improvements and their short-term impact on unemployment. When elasticities of substitution are known or can be estimated with sufficient precision, our paper can be used to predict whether or not product market reforms lead to a decline in aggregate unemployment.

The question of how productivity improvements in one sector affect employment in that sector as well as in the economy as a whole is an old issue in economics. The modern answers date back at least to Baumol [1967]. In his unbalanced productivity model, Baumol analyzed costs per unit of output for fixed wage growth as well as the employment distribution among sectors for fixed output ratios. However, Baumol did not focus on unemployment caused by labor market rigidities.

\footnotetext{
${ }^{2}$ An overview of the potential impact of regulatory reform in product markets in Europe can be found in OECD (1997). The ongoing changes in production technologies can be interpreted as a third paradigm - sometimes called agile production - which replaces craft or mass production to some extent [see Baily and Gersbach 1995]. The transition towards a new production paradigm has potentially large effects on wage and employment, and may raise the wage and job opportunities of some workers relative to others [see e.g. Lindbeck and Snower 1995, Lindbeck and Snower 1996].
} 
Analyzing the effects of restructuring state-owned industries, Blanchard recently explored how labor-saving productivity improvement can cause unemployment with fixed real wages [Blanchard 1998]. The recent literature has emphasized that the relationship between technical progress and unemployment may be ambiguous. Aghion and Howitt (1994 and 1998) have examined a model in which technological progress makes old skills obsolete and forces former workers to train and move elsewhere, which may increase unemployment. ${ }^{3}$

A two-sector model in which technical progress alternatively raises sectoral productivity has been developed by Cohen and Saint-Paul [1997]. Goods are assumed to be complements, and consequently higher productivity in one sector leads to a fall in the corresponding prices. By introducing labor-market imperfections such as bargaining and costly worker re-allocation, the dynamic model shows job destruction in the sector which benefits from technical progress and job creation in the less productive sector.

Our model treats this topic in a simplified manner, because we do not endogenize technical progress. Rather, we allow for arbitrary combinations of elasticities of substitution on the demand side and in the production sectors which allow us to clarify the link between uneven technical progress and unemployment. In the next section the basic model shall be outlined. Chapters 3 and 4 discuss the impacts caused by uneven technical progress on unemployment. Chapters 5 and 6 summarize and conclude.

\footnotetext{
${ }^{3} \mathrm{~A}$ different approach has been developed by Peretto (1999). Here innovations are introduced by existing firms that do not drive other firms out of the market. In this case, higher growth may lead to higher unemployment.
} 


\section{The Model}

We explore a simple model analyzing the employment effects caused by uneven technical change for any combination of substitution elasticities on the demand side and in both production sectors. Our model consists of two sectors, with technological progress taking place in sector 1 . Inputs into production in both industries are labor and capital. ${ }^{4}$ The production functions are of the CES type:

$$
\begin{gathered}
q_{1}=C\left(\beta\left(A L_{1}\right)^{\frac{\sigma_{1}-1}{\sigma_{1}}}+(1-\beta)\left(B K_{1}\right)^{\frac{\sigma_{1}-1}{\sigma_{1}}}\right)^{\frac{\sigma_{1}}{\sigma_{1}-1}} \\
q_{2}=\left(\beta L_{2}^{\frac{\sigma_{2}-1}{\sigma_{2}}}+(1-\beta) K_{2}^{\frac{\sigma_{2}-1}{\sigma_{2}}}\right)^{\frac{\sigma_{2}}{\sigma_{2}-1}}
\end{gathered}
$$

Subscripts 1 and 2 denote the first and second sector, respectively. $\sigma_{1}$ and $\sigma_{2}$ are the corresponding elasticities of substitution between production factors in sector 1 and 2. We assume that technical progress takes place in sector 1 , whereas the rest of the economy, i.e. sector 2 , remains unchanged. We distinguish between a rise in total factor productivity (a rise in C), labor saving technical progress (a rise in A) and capital saving technical progress (a rise in B). They correspond to the three standard forms discussed in the literature: Hicks neutral, Harrod neutral and Solow neutral technical change, respectively.

We assume that labor is supplied inelastically for the whole economy. ${ }^{5}$ Total labor supply is $\bar{L}$. As we are analyzing short-term effects of uneven technical change, capital in either sector is also assumed to be inelastically supplied. In contrast to labor, capital in our model is assumed to be industry-specific. This essentially means that the physical capital is immobile across sectors. The total supply is given by $\bar{K}_{1}$ and $\bar{K}_{2}$, respectively. We assume that price-taking firms in each industry compete for the available capital that is supplied inelastically. An alternative framework runs as follows. Firms in each sector can obtain capital in a "global" market at price $r^{*}$ when capital is supplied completely elastically. Our main argument for the case of Cobb-

\footnotetext{
${ }^{4}$ Capital can include physical and human capital.

${ }^{5}$ Our model could be complemented by a labor/leisure tradeoff. Since we focus on employment rather than on aggregate output, adding a labor/leisure tradeoff would not affect our basic results.
} 
Douglas production functions holds in this framework as well, since firms adjust capital optimally. ${ }^{6}$

We assume that all types of households have the same CES utility function, so that aggregate demand by households can be derived from a representative consumer with the utility function:

$$
u=\left(\alpha c_{1}^{\frac{\sigma_{u}-1}{\sigma_{u}}}+(1-\alpha) c_{2}^{\frac{\sigma_{u}-1}{\sigma_{u}}}\right)^{\frac{\sigma_{u}}{\sigma_{u}-1}}
$$

$c_{1}$ and $c_{2}$ denote the consumption levels of good 1 and good 2. $\sigma_{u}$ is used to denote the elasticity of substitution between the two goods.

The institution in the labor market upon which we focus, is an exogenously given real wage $\overline{r w}$ for workers in either sector. At the beginning, we assume the real wage to exceed the market clearing level, which means that it is binding and leads to unemployment. That is, throughout the paper, we assume $\bar{L}>L_{1}+L_{2}$ except in a special case where $L_{1}+L_{2}$ can exhaust $\bar{L}$. The nominal wage $w$ is equal to $p \cdot \bar{r} w$, where $p$ denotes the price index. A variety of regulations can cause a real wage floor: explicit minimum wages, an unemployment benefit system or institutional wage settings. Our focus is the interaction between technological progress and unemployment. Thus, any motivation for real wages to be set above market clearing levels serves our purpose.

\subsection{The System of Equations}

The equilibrium with real wage rigidities is determined by the following system of equations. Using utility maximization, we obtain the following demand functions for goods 1 and 2 :

$$
c_{1}=\frac{b}{p_{1}+p_{2}\left(\frac{p_{1}(1-\alpha)}{p_{2} \alpha}\right)^{\sigma_{u}}}
$$

\footnotetext{
${ }^{6}$ Other results in our paper, however, would need to be modified in the presence of completely elastic capital supply.
} 


$$
c_{2}=\frac{b}{p_{2}+p_{1}\left(\frac{p_{2} \alpha}{p_{1}(1-\alpha)}\right)^{\sigma_{u}}}
$$

$b$ denotes the households' budget. In order to derive the aggregated demand function of the representative consumer, we must replace the budget $b$ by the aggregate income of the whole economy (the CES demand functions are unit-elastic with respect to income). Therefore, we set $b=p_{1} q_{1}+p_{2} q_{2}$.

In each industry we consider a representative firm that takes the wage and the capital cost in the sector as given. As was previously noted, the physical capital is industryspecific and thus immobile while labor is mobile across sectors. The industries' profit functions are sales with factor costs subtracted:

$$
\begin{aligned}
& \pi_{1}=p_{1} q_{1}-w L_{1}-r_{1} K_{1} \\
& \pi_{2}=p_{2} q_{2}-w L_{2}-r_{2} K_{2}
\end{aligned}
$$

We assume all goods markets and the capital market to be perfectly competitive. Additionally, firms are assumed to be price takers in the labor market. By taking the derivative of profits 1 and 2 with respect to the production factors $L_{1}, K_{1}, L_{2}$ and $K_{2}$ for $\sigma_{1} \neq 1$ and $\sigma_{2} \neq 1$, we obtain four first-order conditions for profit maximization:

$$
\begin{gathered}
\frac{\partial \pi_{1}}{\partial L_{1}}=p_{1} \beta C A^{\frac{\sigma_{1}-1}{\sigma_{1}}} \cdot q_{1}^{\frac{1}{\sigma_{1}}} \cdot L_{1}^{\frac{-1}{\sigma_{1}}}-w=0 \\
\frac{\partial \pi_{1}}{\partial K_{1}}=p_{1}(1-\beta) C B^{\frac{\sigma_{1}-1}{\sigma_{1}}} \cdot q_{1}^{\frac{1}{\sigma_{1}}} \cdot K_{1}^{\frac{-1}{\sigma_{1}}}-r_{1}=0 \\
\frac{\partial \pi_{2}}{\partial L_{2}}=p_{2} \beta q_{2}^{\frac{1}{\sigma_{2}}} \cdot L_{2}^{\frac{-1}{\sigma_{2}}}-w=0 \\
\frac{\partial \pi_{2}}{\partial K_{2}}=p_{2}(1-\beta) q_{2}^{\frac{1}{\sigma_{2}}} \cdot K_{2}^{\frac{-1}{\sigma_{2}}}-r_{2}=0
\end{gathered}
$$

Market clearing for good 1 implies: 


$$
c_{1}=q_{1}
$$

Inserting the aggregated income of the whole economy $\left(p_{1} q_{1}+p_{2} q_{2}\right)$ into the budget entering the demand function $c_{1}$, we obtain the following equivalent condition for market clearing:

$$
c_{1}=q_{1}=\frac{p_{1} q_{1}+p_{2} q_{2}}{p_{1}+p_{2}\left(\frac{p_{1}(1-\alpha)}{p_{2} \alpha}\right)^{\sigma_{u}}}
$$

In the case where $\sigma_{u}>0$ we can write the market clearing as:

$$
\frac{p_{2}}{p_{1}}=\left(\frac{1-\alpha}{\alpha}\right)\left(\frac{q_{1}}{q_{2}}\right)^{\frac{1}{\sigma_{u}}}
$$

The appropriate consumer price index is defined by (see e.g. Dixon and Rankin [1995])

$$
p=\left[\frac{\alpha^{\sigma_{u}}}{\alpha^{\sigma_{u}}+(1-\alpha)^{\sigma_{u}}} p_{1}^{\left(1-\sigma_{u}\right)}+\frac{(1-\alpha)^{\sigma_{u}}}{\alpha^{\sigma_{u}}+(1-\alpha)^{\sigma_{u}}} p_{2}^{\left(1-\sigma_{u}\right)}\right]^{\left(\frac{1}{1-\sigma_{u}}\right)}
$$

This price index guarantees that changes in prices do not affect the households' utility as long as real incomes remain constant. Nominal minimum wages for workers in both industries are therefore given by:

$$
w=\overline{r w} \cdot p
$$

Moreover, market clearing in the capital market requires

$$
\begin{aligned}
& K_{1}=\bar{K}_{1} \\
& K_{2}=\bar{K}_{2}
\end{aligned}
$$

Finally, we normalize the price of the second good to 1, i.e.

$$
p_{2}=1
$$

The equilibrium is determined by the system of equations $4,5,8,9,10,11,13,14$, 1516,17 . The unknown variables are $c_{1}, c_{2}, L_{1}, K_{1}, r_{1}, L_{2}, K_{2}, r_{2}, p_{1}, p, w$. Since 
capital is supplied inelastically in each sector, market clearing implies that $K_{1}$ and $K_{2}$, demanded by the representative firms in each sector are equal to $\overline{K_{1}}$ and $\overline{K_{2}}$. We shall continue working directly with the equilibrium values $K_{1}$ and $K_{2}$ without using the $\overline{K_{1}}$ and $\overline{K_{2}}$ notation.

Obviously, we assume in general that each sector contains more than one firm. In this case, the derivation of the equilibrium must be adjusted accordingly. That is we would

obtain $K_{1}=\frac{\bar{K}_{1}}{n_{1}}$ and $K_{2}=\frac{\bar{K}_{2}}{n_{2}}$, where $n_{1}$ and $n_{2}$ are the number of firms in sector 1 and 2, respectively. Note that prices of industry-specific capital are only relevant to our arguments in the next section. In the polar cases of section 4, the argument does not depend on the equilibrium reactions of $r_{1}$ and $r_{2}$.

\section{Technical Progress: Cobb-Douglas Production Func- tions}

In this section, we consider our benchmark case, in which all production functions are Cobb-Douglas, i.e. $\sigma_{1}=\sigma_{2}=1$. In this case, we cannot differentiate between a rise in total factor productivity (tfp), labor saving or capital-saving technical progress in sector 1, as all types of technical progress are equivalent. In general, such uneven productivity improvements have two direct impacts on employment. First, marginal productivity of labor in sector 1 increases, which has a positive impact on employment using a fixed real wage regime. Second, due to higher productivity in sector 1, the price of good 1 falls relative to the price in sector 2 . This has negative consequences for employment in sector 1 and positive employment effects in sector 2. We will always focus on a situation when there is unemployment in both sectors before the productivity improvements in sector 1 take place. For the Cobb-Douglas case we obtain:

\section{Proposition 1}

Suppose $\sigma_{1}=\sigma_{2}=1$ in the two-sector economy. Then, a rise of productivity in sector 1 raises aggregate employment.

The proof is given in the appendix. The reasoning runs as follows: as the productivity of industry 1 increases, the production of good 1 and 2 increase as well, which in turn increases the real income of the whole economy. The same Cobb-Douglas functions in 
both sectors imply that the income distribution must remain identical with $\beta$ being the share of labor. With a fixed real wage, an increase in real income means that the employment rate must be higher. ${ }^{7}$

It is unnecessary to make assumptions about the elasticity of substitution in the utility function $\sigma_{u}$ in order for proposition 1 to hold. The elasticity determines in which sector the positive employment effect takes place. Proposition 1 only shows that aggregate employment increases, without specifying the sector.

In what follows, we demonstrate that the aggregate employment effect can be positive or negative for any type of technical change. We identify polar cases where technological progress of any kind strongly decreases or increases aggregate unemployment (compared to the Cobb-Douglas case).

\section{Technical Progress: Polar Cases}

\subsection{A Rise in Total Factor Productivity}

We have established that for our benchmark case, i.e. the Cobb-Douglas production functions with "intermediate" elasticities of substitution, uneven technical progress always increases the aggregate demand for labor for a given real wage. We now go on to show that aggregate employment can also decrease when uneven Hicks neutral technical progress takes place. We will continue with a discussion of the circumstances in which the increase of employment is even higher than in the benchmark case. All of the following facts refer to the two-sector model outlined in section 2. We obtain

\section{Fact 1:}

A rise in tfp in sector 1 leads to higher unemployment provided the elasticities of substitution on the demand side and the production factors in the remaining sector are sufficiently small.

\footnotetext{
${ }^{7}$ So far we have assumed that the unemployed have no income. Introducing unemployment benefits that are lower than the minimum real wage would not change our arguments.
} 
Fact 1 follows from the following considerations. Let $\sigma_{u}$ and $\sigma_{2} \rightarrow 0$. Production in sector 2 becomes thus Leontief:

$$
q_{2}=\min \left(L_{2}, K_{2}\right)
$$

The profits of industry 2 could thus be written as

$$
\pi_{2}=p_{2} K_{2}-w L_{2}-r_{2} K_{2}
$$

If capital is binding, any further worker employed cannot increase output. Hence, the first-order condition with respect to labor in this case is

$$
\frac{\partial \pi_{2}}{\partial L_{2}}=-w=0
$$

and thus $w=0$. This reflects that the marginal productivity of any further worker employed in sector 2 would be zero if capital is binding, so that nobody else can be employed there for the given real wage. Thus, with fixed capital, production of $q_{2}$ cannot increase. Since $\sigma_{u} \rightarrow 0$, the utility function becomes

$$
u=\min \left(c_{1}, c_{2}\right)
$$

As $q_{2}$ cannot increase, $q_{1}$ cannot increase either, since otherwise marginal utility and thus $p_{1}$ and $w$ would go to zero. This follows from the market clearing condition (13). If $q_{1}>q_{2}$ we obtain $p_{1}=0$ for $\sigma_{u} \rightarrow 0$. As can be seen from the first-order condition for profit maximization (8), this would cause the value of marginal productivity of labor in sector 1 to be zero, i.e. $w=0$. The latter cannot be an equilibrium as $w=\overline{r w} \cdot p>0$ because $p_{2}=1$ and thus $p$ cannot become zero. However, a higher tfp in sector 1 implies that, ceteris paribus, production of good 1 tends to increase. Consequently, $L_{1}$ must decrease in order to prevent this since $K_{1}$ remains unchanged, which establishes fact 1 .

We continue with an analysis of the opposite extreme, where a rise of $t f p$ causes a very large positive employment effect. 


\section{Fact 2:}

A sufficient rise in tfp leads to a higher employment level than in the benchmark case provided the elasticities of substitution on the demand side and the production factors in sector 1 are sufficiently high.

To establish fact 2, let $\sigma_{u}$ and $\sigma_{1} \rightarrow \infty$. From the market clearing condition (13), we observe that $p_{1}=\frac{\alpha}{1-\alpha}$ if $\sigma_{u} \rightarrow \infty$, independent of the quantities $q_{1}$ and $q_{2}$. This is caused by the perfect substitution for $\sigma_{u} \rightarrow \infty$, implying a utility function with constant marginal utility of the type:

$$
u=\alpha c_{1}+(1-\alpha) c_{2}
$$

When $\sigma_{1} \rightarrow \infty$ as well, production in sector 1 also becomes substitutional implying constant marginal productivity of the production factors:

$$
q_{1}=C\left(\beta L_{1}+(1-\beta) K_{1}\right)
$$

We have set $\mathrm{A}=\mathrm{B}=1$ in this case. If there is a higher employment level in sector 1 , neither the marginal product of labor nor the price of good 1 will decrease. We now examine the profit function of industry 1:

$$
\pi_{1}=p_{1} \cdot C\left(\beta L_{1}+(1-\beta) K_{1}\right)-w L_{1}-r_{1} K_{1}
$$

The first-order condition for profit maximization with respect to labor is

$$
\frac{\partial \pi_{1}}{\partial L_{1}}=p_{1} C \beta-w=0
$$

Now consider a scenario with a binding nominal wage

$$
w=\overline{r w} \cdot p>p_{1} C \beta
$$


before the increase of $\mathrm{C}$ and

$$
w=\overline{r w} \cdot p \leq p_{1} C \beta
$$

after a sufficient increase of $\mathrm{C}$. This implies that before the tfp improvement there is zero employment in sector 1 and after the improvement there is full employment. ${ }^{8}$ The example in fact 2 is an extreme case and serves only to illustrate the implications of the more realistic case where $\sigma_{1}$ and $\sigma_{u}$ are large, but finite.

\subsection{Labor-Saving Technical Progress}

In this subsection we study labor-saving technical progress. We wish to demonstrate, as in all other cases, that the direction of employment development depends crucially on the elasticities of substitution.

\section{Fact 3:}

Labor-saving technical progress in sector 1 leads to an increase in unemployment provided the elasticity of substitution between production factors in sector 1 is sufficiently small.

We assume $\sigma_{1} \rightarrow 0$, i.e. let $q_{1}$ be Leontief:

$$
q_{1}=\min \left(A L_{1}, K_{1}\right)
$$

where we have set $\mathrm{B}=\mathrm{C}=1$. Suppose that capital is binding. When $\mathrm{A}$ increases, capital remains binding. Hence, from the profit function

$$
\pi_{1}=p_{1} K_{1}-w L_{1}-r_{1} K_{1}
$$

we obtain the first-order condition as

\footnotetext{
${ }^{8}$ Note that sector 2 is not affected by the productivity change.
} 


$$
\frac{\partial \pi_{1}}{\partial L_{1}}=-w=0
$$

Therefore, we would have $\mathrm{w}=0$. This implies that, in order to achieve positive labor income, $L_{1}$ must decrease. This is not compensated by higher employment in sector 2 . Note that we have not used any price adjustments in this argument, i.e. the magnitude of $\sigma_{u}$ is not essential. Therefore, our argument also holds in a one-sector economy where no relative goods-price changes can occur (see also Blanchard [1998]). We continue with a consideration of the opposite case in which the elasticity of substitution between production factors in sector 1 is high.

\section{Fact 4:}

A sufficiently large labor-saving technical change leads to a more extreme employment level increase than in the benchmark case provided the elasticities of substitution are sufficiently high on the demand and supply side in sector 1.

In order to show fact 4 , let $\sigma_{u}$ and $\sigma_{1} \rightarrow \infty$. We obtain, once again, $p_{1}=\frac{\alpha}{1-\alpha}=$ constant for $\sigma_{u} \rightarrow \infty$ from the market clearing equation (13). In the case of the substitutional production function we obtain the profit

$$
\pi_{1}=p_{1}\left(\beta A L_{1}+(1-\beta) K_{1}\right)-w L_{1}-r_{1} K_{1}
$$

where we set $\mathrm{B}=\mathrm{C}=1$. The first-order condition yields

$$
\frac{\partial \pi_{1}}{\partial L_{1}}=p_{1} \beta A-w=0
$$

We again consider the constellation

$$
\overline{r w} \cdot p>p_{1} \beta A
$$

before the increase of $\mathrm{A}$ and

$$
\overline{r w} \cdot p \leq p_{1} \beta A
$$


after a sufficiently large increase. This means that in the first sector nobody is employed before the labor-saving improvement and everybody (up to full employment) is employed afterwards. This establishes fact 4 since employment does not change in sector 2 .

Fact 4 illustrates the extreme case where productivity improvements increase the marginal (equal to the average) product of labor until it is above the real reservation wage. As a consequence of the linear technology, all workers can be employed after technological progress has taken place in sector 1.

\subsection{Capital-Saving Technical Progress}

Finally, we examine capital-saving technical progress. Our scenarios start with positive employment in both sectors. Again we demonstrate that both positive and negative consequences for employment may occur by considering polar cases.

\section{Fact 5:}

Capital-saving technical progress leads to a decrease in employment provided the elasticities of substitution on the demand and supply side in sector 2 are sufficiently low.

In order to show fact 5 , let $\sigma_{u} \rightarrow 0$. According to the market clearing condition (13), we must have $q_{1}=q_{2}$. Otherwise $p_{1}$ would be zero or infinity. In the first (second) case there can be no employment in sector 1 (sector 2) and therefore one sector is inactive which we have excluded.

Moreover, let $\sigma_{2} \rightarrow 0$. Now suppose that $\mathrm{B}$ increases. For $\sigma_{1}>0, q_{1}$ rises, ceteris paribus. The market clearing condition (13) implies that $q_{2}$ would rise as well. With $\sigma_{2}=0$, capital being binding and fixed production factors in sector $2, q_{2}$ cannot rise and no more workers can be employed there. Hence, $q_{1}$ cannot increase either, because otherwise $p_{1}$ would immediately approach 0 , as would the wages in sector 1 . As real wages are given by $\overline{r w}, L_{1}$ must decline instead. The situation is different when the elasticity of substitution between the consumption goods is high. In this case we obtain: 


\section{Fact 6:}

Capital-saving technical progress enhances employment more than in the benchmark case provided the elasticity of substitution on the demand side is sufficiently high.

In order to establish fact 6 , let $\sigma_{u} \rightarrow \infty$, such that a higher production of good 1 does not lead to a price decline for the good. Now, if $\sigma_{1}<\infty$, an increase of B increases marginal productivity of labor in sector 1 . Thus, with real wages given by $\overline{r w}$, employment must increase in the case of capital-saving technical progress. The increase is the highest in the case of $\sigma_{1}=0$.

\section{Summary of the Results}

The results of the six facts are summarized in table 1 . The first row of the table shows the (described) constellation of elasticities of substitution leading to an increase of aggregate unemployment for every type of technical progress. The second row shows the constellations that lead to a stronger decrease of aggregate unemployment than in our benchmark case with Cobb-Douglas production functions.

Table 1 illustrates that for every type of technological progress, a suitable combination of elasticities on the demand side and elasticities in sector 1 and sector 2 may increase aggregate unemployment. While low elasticities of substitution between consumption goods generally tend to imply a negative relationship between productivity improvement and employment, high substitution elasticities of demand may lead to strongly positive reactions of employment. Of course, we have by no means exhausted all the interesting constellations of substitution elasticities on the supply and demand side. Our objective was simply to illustrate that any relationship between productivity improvements and unemployment can occur. 
Table 1:

\begin{tabular}{|l|l|l|l|}
\hline & $\begin{array}{l}\text { total factor } \\
\text { productivity } \\
\text { improvement }\end{array}$ & $\begin{array}{l}\text { labor-saving tech- } \\
\text { nical progress }\end{array}$ & $\begin{array}{l}\text { capital-saving } \\
\text { technical } \\
\text { progress }\end{array}$ \\
\hline $\begin{array}{l}\text { increase of aggregate } \\
\text { unemployment }\end{array}$ & $\sigma_{u} \rightarrow 0, \sigma_{2} \rightarrow 0$ & $\sigma_{1} \rightarrow 0$ & $\sigma_{u} \rightarrow 0, \sigma_{2} \rightarrow 0$ \\
\hline $\begin{array}{l}\text { strong decrease of ag- } \\
\text { gregate unemployment }\end{array}$ & $\sigma_{u} \rightarrow \infty, \sigma_{1} \rightarrow \infty$ & $\sigma_{u} \rightarrow \infty, \sigma_{1} \rightarrow \infty$ & $\sigma_{u} \rightarrow \infty, \sigma_{1} \rightarrow 0$ \\
\hline
\end{tabular}

\section{Conclusion}

Since technical change does often not affect an economy in a uniform way, we have analyzed the (short-term) effects of uneven technical progress. In a simple two-sector model with real wage rigidity, we have examined the impact on unemployment of rising total factor productivity, labor saving and capital saving technological progress. We have shown that for every type of uneven technical change, aggregate unemployment may rise or fall, depending on the elasticities of substitution on the supply and demand side.

Apart from technical progress, our analysis could be used to study the impact of uneven productivity improvements, which usually take place when state-owned firms are privatized and restructured as in transition economies. Whether or not, for instance, large-scale restructuring exercises in transition economies raise aggregate unemployment depends entirely on the combination of elasticities of substitution in the reorganized sector, in the rest of the economy and on the demand side. 


\section{References}

[1] Aghion, P. and P. Howitt (1994), "Growth and Unemployment", Review of Economic Studies, 61, 477-494.

[2] Aghion, P. and P. Howitt (1998), "Endogenous Growth Theory", MIT University Press, Cambridge, MA.

[3] Anderson, T.M. (2000), "Product Market Integration, Wage Dispersion and Unemployment", mimeo, University of Arhus.

[4] Ark, B. van and D. Pilat (1993), "Cross Country Productivity Levels: Differences and Causes", Brookings Papers on Economic Activity: Microeconomics, 2, 1-68.

[5] Baily, M.N. (1993), "Competition, Regulation and Efficiency in Service Industries", Brookings Papers on Economic Activity: Microeconomics, 2, pp. 71-159.

[6] Baily, M.N. and H. Gersbach (1995), "Efficiency in Manufacturing and the Need for Global Competition", Brookings Papers on Economic Activity: Microconomics, 307-358.

[7] Baumol, W.J. (1967): "Macroeconomics of Unbalanced Growth: The Anatomy of Urban Crisis", The American Economic Review, 3, pp. 415-426.

[8] Baumol, W.J., S.A.B. Blackman, and E.N. Wolff (1989), "Productivity and American Leadership, The Long Run View", MIT Press, Cambridge, MA.

[9] Blanchard, O. (1998): "The Economics of Post-Communist Transition", Clarendon Press, Oxford

[10] Börsch-Supan, A. (1999), "Capital's Contribution to Productivity and the Nature of Competition", Brookings Papers on Economic Activity.

[11] Burda, M. (1999): "Product Market Regulation and Labor Market Outcomes: How can Deregulation Create Jobs?", mimeo, Humboldt University.

[12] Cohen, D. and G. Saint-Paul (1997): "Uneven Technical Progress and Job Destructions", mimeo. 
[13] Dixon, H.D., Rankin (1995): "The New Macroeconomics: Imperfect Markets and Policy Effectiveness", Cambridge University Press, Cambridge, UK.

[14] Dollar, D. and E.N. Wolff (1993), "Competitiveness, Convergence, and International Specialization", MIT Press, Cambridge, MA.

[15] Gersbach, H. and G. Sheldon (1996), "Structural Reforms and their Implications for Macroeconomic Policies", OECD Proceedings, 131-167.

[16] Gersbach, H. (2000), "Promoting Product Market Competition to Reduce Unemployment in Europe: An Alternative Approach? Product Market Competition, Unemployment and Income Disparities", Kyklos, 53 (2), 117-133.

[17] Green, A. and D. Mayes (1991), "Technical Inefficiency in Manufacturing Industries", Economic Journal, 101, 523-538.

[18] Hay, D.A. and G.S. Liu (1997), "The Efficiency of Firms: What Difference does Competition Make?", Economic Journal, 107, 597-617.

[19] Lindbeck, A. and D.J. Snower (1995), "Restructuring Production and Work", CEPR Discussion Paper.

[20] Lindbeck, A. and D.J. Snower (1996), "Reorganisation of Firms and Labor Market Inequality", CEPR Discussion Paper.

[21] Nickell, S. (1996), "Competition and Corporate Performance", Journal of Political Economy, 104, 724-746.

[22] Nickell, S. (1999), "Product Markets and Labour Markets", Labour Economics, 6, $1-20$.

[23] OECD (1997), "The OECD Report on Regulatory Reform", Vol. I and II, OECD, Paris.

[24] Peretto, P.F. (1999), "Market Power, Growth and Unemployment", Duke University, Durham, NC, mimeo. 


\section{Appendix}

\section{Proof of Proposition 1:}

We consider the following Cobb-Douglas production functions: ${ }^{9}$

$$
\begin{aligned}
& q_{1}=C L_{1}^{\beta} K_{1}^{1-\beta} \\
& q_{2}=L_{2}^{\beta} K_{2}^{1-\beta}
\end{aligned}
$$

In the Cobb-Douglas case, the first-order conditions for profit maximization in sector 1 and 2 with respect to labor and capital are:

$$
\begin{gathered}
w=p_{1} C \beta L_{1}^{(\beta-1)} K_{1}^{(1-\beta)} \\
w=\beta L_{2}^{(\beta-1)} K_{2}^{(1-\beta)} \\
r_{1}=p_{1} C(1-\beta) L_{1}^{\beta} K_{1}^{-\beta} \\
r_{2}=(1-\beta) L_{2}^{\beta} K_{2}^{-\beta}
\end{gathered}
$$

Note that firms are price takers with respect to all production factors. Therefore, the Cobb-Douglas nature of production implies $w L_{1}=\beta p_{1} q_{1}, w L_{2}=\beta q_{2}, r_{1} K_{1}=$ $(1-\beta) p_{1} q_{1}$ and $r_{2} K_{2}=(1-\beta) q_{2}$, which follows from the first-order conditions above. The fact that the labor and capital shares are constant in each sector will be important later in the proof.

Dividing the first-order condition (36) by (37) yields

$$
1=p_{1} C\left(\frac{L_{1}}{L_{2}}\right)^{\beta-1}\left(\frac{K_{1}}{K_{2}}\right)^{1-\beta}
$$

which leads to

\footnotetext{
${ }^{9}$ Since all types of technical progress are equivalent, a single parameter $C$ for comparative statics is sufficient.
} 


$$
p_{1}=\frac{1}{C}\left(\frac{L_{1}}{L_{2}}\right)^{1-\beta}\left(\frac{K_{2}}{K_{1}}\right)^{1-\beta}
$$

The market clearing condition (13) is given by

$$
\begin{aligned}
p_{1} & =\left(\frac{\alpha}{1-\alpha}\right)\left(\frac{q_{2}}{q_{1}}\right)^{\frac{1}{\sigma_{u}}} \\
& =\left(\frac{\alpha}{1-\alpha}\right)\left(\frac{1}{C}\right)^{\frac{1}{\sigma_{u}}}\left(\frac{L_{2}}{L_{1}}\right)^{\frac{\beta}{\sigma_{u}}}\left(\frac{K_{2}}{K_{1}}\right)^{\frac{1-\beta}{\sigma_{u}}}
\end{aligned}
$$

implying

$$
\left(\frac{L_{1}}{L_{2}}\right)^{1-\beta}=p_{1}^{\frac{\sigma_{u}(\beta-1)}{\beta}}\left(\frac{1-\alpha}{\alpha}\right)^{\frac{\sigma_{u}(\beta-1)}{\beta}} C^{\frac{\beta-1}{\beta}}\left(\frac{K_{2}}{K_{1}}\right)^{\frac{(1-\beta)^{2}}{\beta}}
$$

Inserting this into 41 yields

$$
p_{1}=\frac{1}{C}\left(\frac{K_{2}}{K_{1}}\right)^{1-\beta} p_{1}^{\frac{\sigma_{u}(\beta-1)}{\beta}}\left(\frac{1-\alpha}{\alpha}\right)^{\frac{\sigma_{u}(\beta-1)}{\beta}} C^{\frac{\beta-1}{\beta}}\left(\frac{K_{2}}{K_{1}}\right)^{\frac{(1-\beta)^{2}}{\beta}}
$$

Solving for $p_{1}$ we obtain

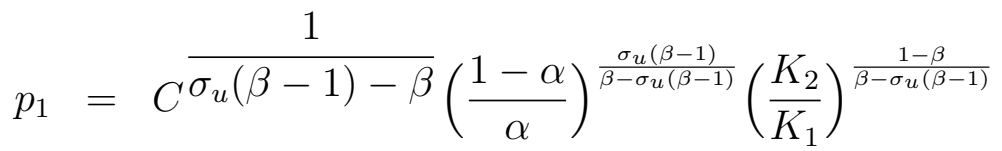

$$
\begin{aligned}
& =C^{\frac{1}{\sigma_{u}(\beta-1)-\beta}} \cdot \text { const. }
\end{aligned}
$$

As $0<\beta<1$ and $\sigma_{u} \geq 0$, we have $\frac{\partial p_{1}}{\partial C}<0$.

Solving the first-order condition of profit maximization in sector 2 (eq. 37) for labor demand, we obtain

$$
L_{2}=\left(\frac{\beta}{\overline{r w} p}\right)^{\frac{1}{1-\beta}} K_{2}
$$

with $\overline{r w} p$ being the nominal wage, i.e. fixed real wage $\overline{r w}$ times the price index $p$. As $p_{1}$ decreases with $C$ and $p_{2}=1, p=p\left(p_{1}, p_{2}\right)$ decreases with $C$ as well, implying that $L_{2}$ increases. With fixed capital this means that production in sector 2 increases. 
From the market clearing condition (eq. 42), we observe that in order for $p_{1}$ to decrease $\frac{q_{1}}{q_{2}}$ must increase. Since $q_{2}$ increases, $q_{1}$ must increase as well. Thus, we have an increase of production in sector 1 , too.

As we have an increase in production of good 1 and 2, aggregate real income increases and so does real income received by capital $\left.\left(r_{1} K_{1}+r_{2} K_{2}\right) / p=(1-\beta)\left(p_{1} q_{1}+q_{2}\right)\right) / p$ and real income received by labor $\left.\left(w L_{1}+w L_{2}\right) / p=\beta\left(p_{1} q_{1}+q_{2}\right)\right) / p$. In particular, for the Cobb-Douglas production functions, the constant income share for labor $\beta$ is given by

$$
\beta=\frac{\overline{r w} L_{1}}{\left(p_{1} q_{1}\right) / p}=\frac{\overline{r w} L_{2}}{\left(p_{2} q_{2}\right) / p}=\frac{\overline{r w}\left(L_{1}+L_{2}\right)}{\left(p_{1} q_{1}+p_{2} q_{2}\right) / p}=\frac{w\left(L_{1}+L_{2}\right) / p}{\left(p_{1} q_{1}+p_{2} q_{2}\right) / p}
$$

Since the real income of the economy, i.e. the denominator, increases, $L_{1}+L_{2}$ must increase as well for a fixed real wage $\overline{r w}=\frac{w}{p}$. QED. 


\section{IZA Discussion Papers}

No. Author(s)

463

464

465

466
J. Ermisch

M. Francesconi

\section{J. E. Askildsen}

E. Bratberg

$\varnothing$. A. Nilsen
A. Venturini
C. Villosio
J. Wagner

\section{R. Lalive}

J. C. van Ours

J. Zweimüller
A. Cigno
F. C. Rosati
L. Guarcello

71 B. R. Chiswick

Y. Liang Lee

P. W. Miller

R. Foellmi

J. Zweimüller

J. C. van Ours

J. T. Addison

L. Bellmann

A. Kölling

\section{Z. Hercowitz}

E. Yashiv

W. A. Cornelius

T. Tsuda

M. A. Clark

D. A. Jaeger

H. Gersbach

A. Schniewind
Title

Area

Date

Labor Supply Dynamics, Unemployment and

5

03/02

Human Capital Investments

03/02 the Firm: Lessons from a Hidden Action Model with Endogenous Outside Option

Intergenerational Social Mobility and Assortative 1

Mating in Britain

Unemployment, Labour Force Composition and 1

Sickness Absence: A Panel Data Study

Are Immigrants Competing with Natives in the

1

Italian Labour Market? The Employment Effect

The Impact of Risk Aversion, Role Models, and the Regional Milieu on the Transition from

Unemployment to Self-Employment: Empirical

Evidence for Germany

The Effect of Benefit Sanctions on the Duration 3

of Unemployment

Does Globalisation Increase Child Labour?

Immigrants' Language Skills and Visa Category

Structural Change and the Kaldor Facts of

Economic Growth

A pint a day raises a man's pay, but smoking blows that gain away

Unions, Works Councils and Plant Closings in

3

04/02 Germany

A Macroeconomic Experiment in Mass

04/02 Immigration

Labor Market Incorporation of Immigrants in Japan and the United States: A Comparative Analysis

Natives, the Foreign-Born and High School

the GED 